\title{
Fatal Paratanaisia bragai (Digenea: Eucotylidae) infection in scarlet macaws (Ara macao) in Costa Rica
}

\author{
Alejandro Alfaro-Alarcón ${ }^{1}$, Juan Alberto Morales ${ }^{1}$, Vincenzo Veneziano² and Mario Santoro ${ }^{*}$ \\ ${ }^{1}$ Departamento de Patologia, Escuela de Medicina Veterinaria, Universidad Nacional, Heredia, Costa Rica; \\ ${ }^{2}$ Department of Veterinary Medicine and Animal Production, University of Naples Federico II, Naples, Italy; \\ ${ }^{3}$ Department of Public Health and Infectious Diseases, Section of Parasitology, Sapienza University of Rome, Rome, Italy
}

\begin{abstract}
We report on four fatal cases of renal infection due to Paratanaisia bragai in scarlet macaws (Ara macao) from two rescue centres in Costa Rica. At necropsy, birds had severe dehydration and cachexia. Two birds had hydropericardium, oedematous lungs, and liver lipidic degeneration. All birds had enlarged kidneys with brown pale discoloration and diffuse white spots on the cortical and sliced surfaces. Ureters were filled with many specimens of P. bragai. Histopathologically, the urinary system revealed multifocal interstitial lymphocytic-plasmacytic nephritis, multifocal mineralization of renal tubules, and interstitial fibrosis associated with flukes. Death of all scarlet macaws was related to severe nephritis leading to chronic renal failure due to $P$. bragai infection. It is plausible that $P$. bragai infection of scarlet macaws was accidental due to ingestion of the gastropod intermediate host inside the cages during the rainy season when humidity is higher and gastropods are more active. This represents the second report of parasitism by Eucotylidae digeneans in birds of Psittaciformes and the first in scarlet macaws.
\end{abstract}

\section{Keywords}

Psittaciformes, digeneans, pathological changes, renal system parasitism, renal failure

The digenetic trematode Paratanaisia bragai Santos 1934 (Digenea: Eucotylidae) as an adult is a parasite of kidneys and ureters of birds. Birds are infected by feeding on terrestrial gastropods infected by metacercariae which excyst in the definitive host and mature in the renal system (Keller and Barros-Araujo 1992, Brandolini and Amato 2006). Since its original description in Brazil (Santos 1934), our knowledge of the prevalence and geographical distribution of $P$. bragai has increased dramatically with conflicting reports concerning its pathogenicity (see Unwin et al. 2013). In their usual definitive hosts, including Galliformes, Columbiformes and Anseriformes, Paratanaisia spp. produce generally limited lesions, while in occasional/accidental hosts these flukes may cause severe pathological changes and death (Brener et al. 2006, Luppi et al. 2007, Bunbury et al. 2008, Abdo and Sul$\tan 2013$, Unwin et al. 2013). The only report of Paratanaisia infection in Psittaciformes was from captive birds from Brazil describing fatal granulomatous nephritis by $P$. robusta in a blue and gold macaw (Ara ararauna), and by both $P$. robusta and $P$. bragai in a blue-winged macaw (Propyrrhura maracana), and a white-eared parakeet (Pyrrhura leucotis) respectively (Luppi et al. 2007). Here we describe the fatal infection by P. bragai in four scarlet macaws (Ara macao) in Costa Rica.

The four scarlet macaw cases here presented were all adult individuals ( 3 males and one female). They had an history of captivity ranging from 3 to 8 years, and were housed in cages ( 8 meters high $\times 12-15$ meters long) provided with small trees and grass floor, with a variable numbers of individuals of the same species. They were fed a daily mixed diet of rice, beans, fruits and vegetables. All birds died during the rainy season: two males on June and July 2013, coming from a rescue centre located in Quepos (Puntarenas) on the Pacific coast; the other two on August 2012 coming from a rescue centre in the outskirts of San José City (RCJC), Central Valley of Costa Rica. In this latter rescue centre, another 6 scarlet macaws died during June/August 2013 showing the same poor condition as the four cases here presented. Although P. bragai infection 


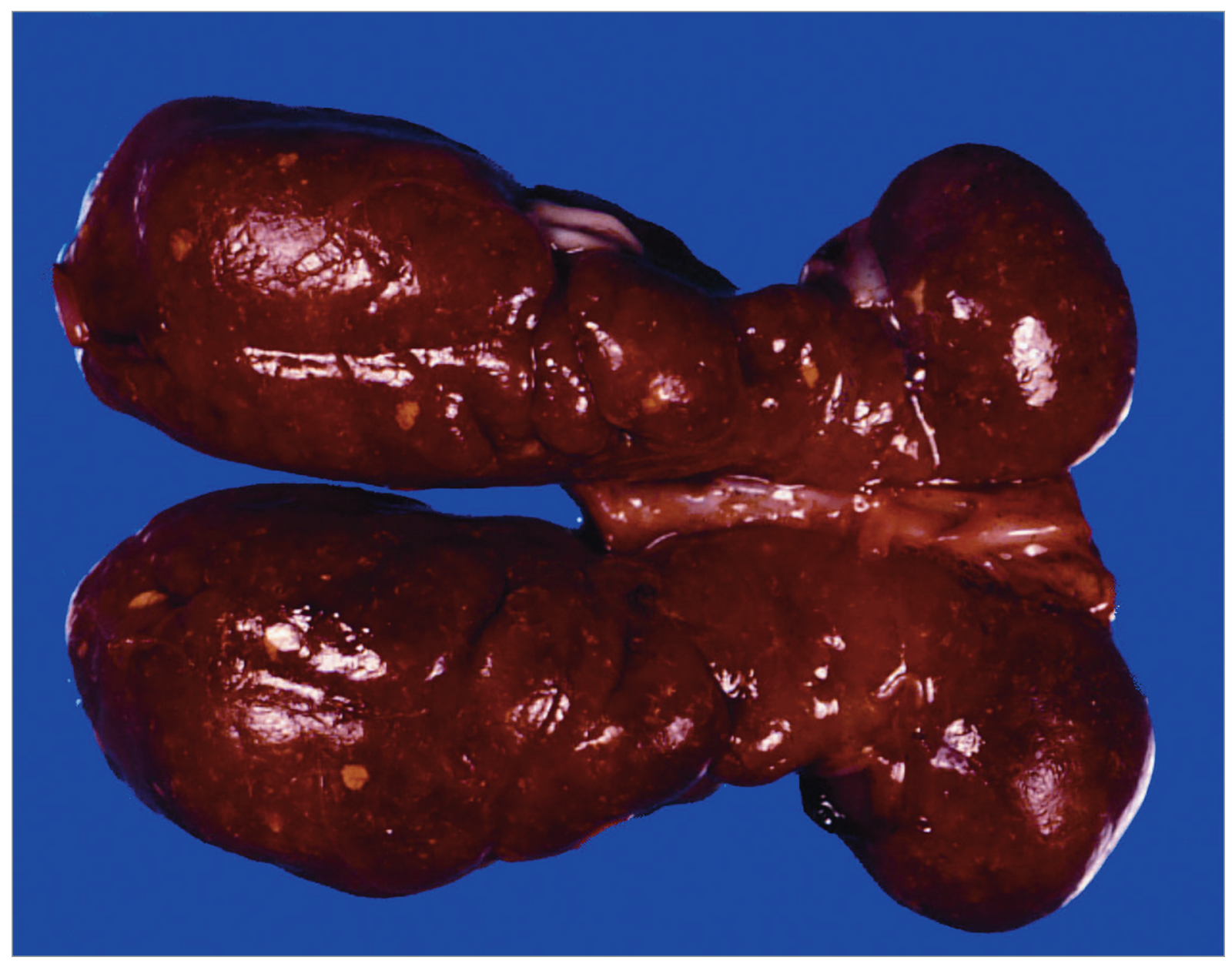

Fig. 1. Enlarged kidneys of a male scarlet macaw (Ara macao) infected by Paratanaisia bragai. Note the diffuse white spots on the cortical surface

was suspected, no necropsies were performed on these 6 birds. Carcasses of the four scarlet macaws were freshly submitted and detailed post-mortem examination was performed to assess the cause of death. During necropsy, the heart, trachea, lungs, air sacs, renal system, spleen, liver, gallbladder, and the whole digestive tract of birds were examined and helminths, when present, were collected and identified. Digeneans were washed in saline solution, fixed in $70 \%$ ethanol, stained with Mayer's acid carmine, and mounted in Canada balsam for identification under light microscopy. Identification of $P$. bragai followed Santos (1934) and Brandolini and Amato (2007). Tissue samples were fixed in 10\% neutral buffered formalin, embedded in paraffin, sectioned at $4 \mu \mathrm{m}$, and stained with haematoxylin and eosin and Masson's trichrome stain. Voucher specimens of P. bragai from the scarlet macaw were deposited in the Natural History Museum in London, U.K. (Accession number: NHMUK 2515.1.29.4-7).

At post-mortem examination, the four scarlet macaws showed cachexia and severe dehydration. Two birds coming from the RCJC, showed hydropericardium, a flaccid and pale myocardium, oedematous lungs, and mild liver lipidic degen- eration. Most significant gross changes were seen in the urinary system of all four birds. Both kidneys were enlarged with brown pale discoloration showing diffuse white spots on the cortical and sliced surface of approximately $1-2 \mathrm{~mm}$ in diameter (Fig. 1). Ureters were increased in size and filled with many digenetic trematodes. Flukes were identified as $P$. bragai and no other parasites were found in the four birds.

Histopathological examination of the urinary system revealed sections of gravid flukes and their eggs in all birds (Figs 2, 3). Morphological features of fluke sections were compatible with those of P. bragai extracted from the ureters. Lesions were similar in all reported cases, and were characterized by multifocal interstitial lymphocytic-plasmacytic nephritis with epithelioid macrophages and a few heterophils and multinucleated giant cells, multifocal mineralization of renal tubules, and interstitial fibrosis (Figs 2, 3). A more prominent granulomatous and fibrosing interstitial nephritis was observed in association with degenerated flukes. Flukes were also observed within the dilated collecting tubules and renal interstitium. The renal medulla collecting tubules were dilated by variable amounts of flukes, and mildly atrophic 
transitional epithelium was also observed. The death of the four scarlet macaws was related to multifocal granulomatous interstitial nephritis leading to chronic renal failure caused by P. bragai infection.

All four scarlet macaws exhibited severe histopathological renal lesions which were directly related to the P. bragai infection. Gross and histopathological lesions seen in scarlet macaws resembled those described previously in three Psittaciformes species (Luppi et al. 2007) suggesting that members of this bird order are highly susceptible to infection with this parasite. In Brazil the recognized intermediate hosts of $P$. bragai are two gastropods of the family Subulinidae, Leptinaria unilamellata and Subulina octona (Keller and Barros-Araujo 1992; Brandolini and Amato 2006). Both species are largely distributed in Costa Rica (Barrientos 2003; Pérez et al. 2005). Brandolini and Amato (2006), demonstrated that in experimentally infected $S$. octona, larval development of P. bragai concluded at 40 days post infection, with encystment of the metacercariae. In chicks fed infected L. unilamellata, the faecal elimination of P. bragai eggs starts 25 days post infection. Five days after observation of eggs in faeces, chicks were necropsied and found to be infected with 12 to 82 gravid digeneans (Keller and Barros-Araujo 1992). On the basis of post-mortem findings here found we may hypothesize that infection was contracted within the previous 1 or 2 months in the same rescue centres. Feeding habits of free-ranging scarlet macaws include fruits, nuts and seeds, but in captivity their feeding habits may change. The curator of the RCJC reported that the scarlet macaws were frequently seen to feed on invertebrates on the ground and trees. It is plausible that P. bragai infection of scarlet macaws was accidental due to ingestion of the gastropod intermediate host inside the cages during the rainy season when humidity is higher and gastropods are more active.

In conclusion, this is the second report of parasitism by trematodes of the family Eucotylidae in the urinary system of psittaciform birds and the first in the scarlet macaw describing fatal infection due to chronic renal failure by P. bragai. Costa

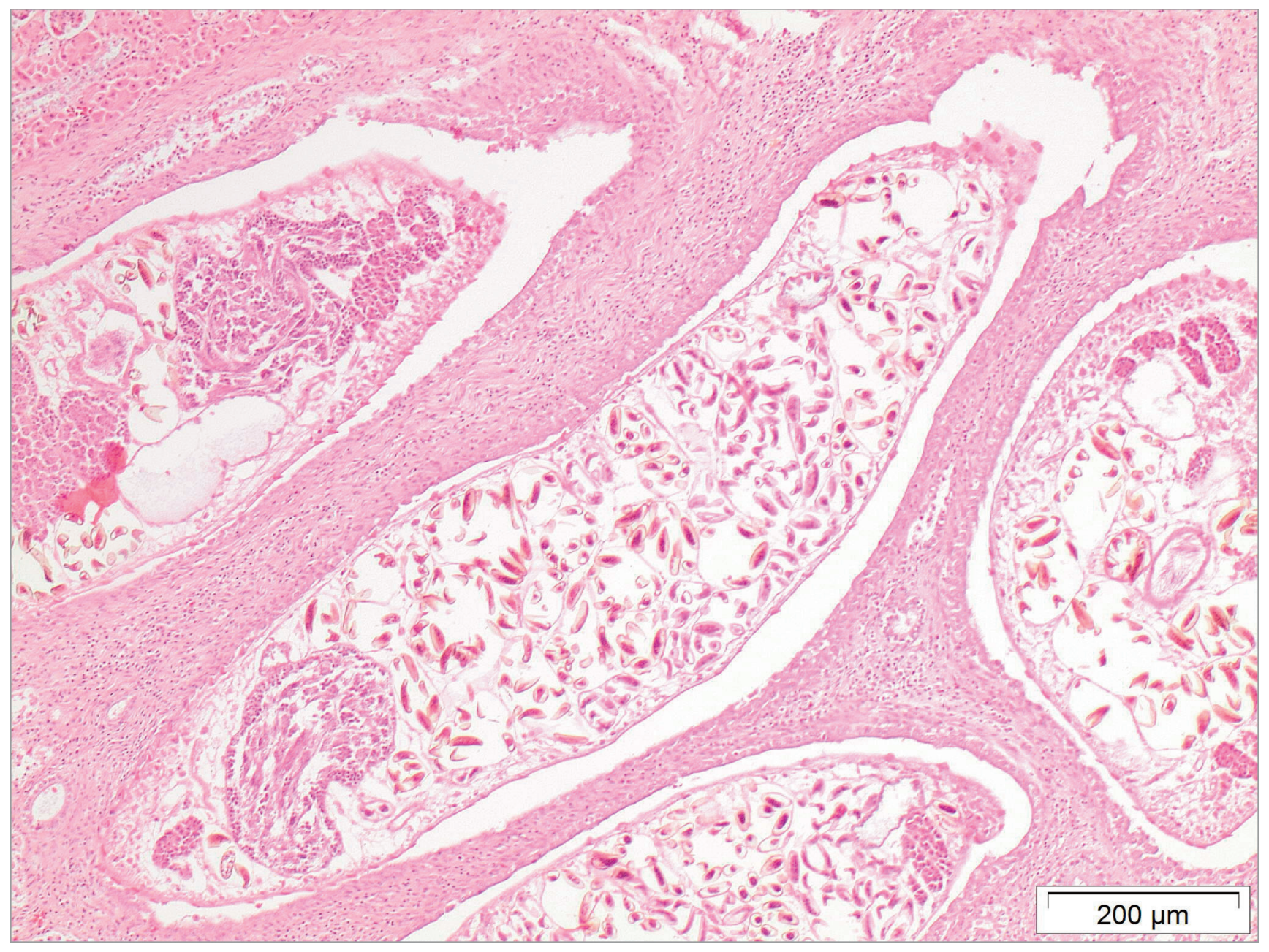

Fig. 2. Cross section of the kidney of a female scarlet macaw (Ara macao) showing gravid specimens of P. bragai in the dilated medullary collecting ducts in association with lympho-plasmacytic inflammation. Haematoxylin and eosin 


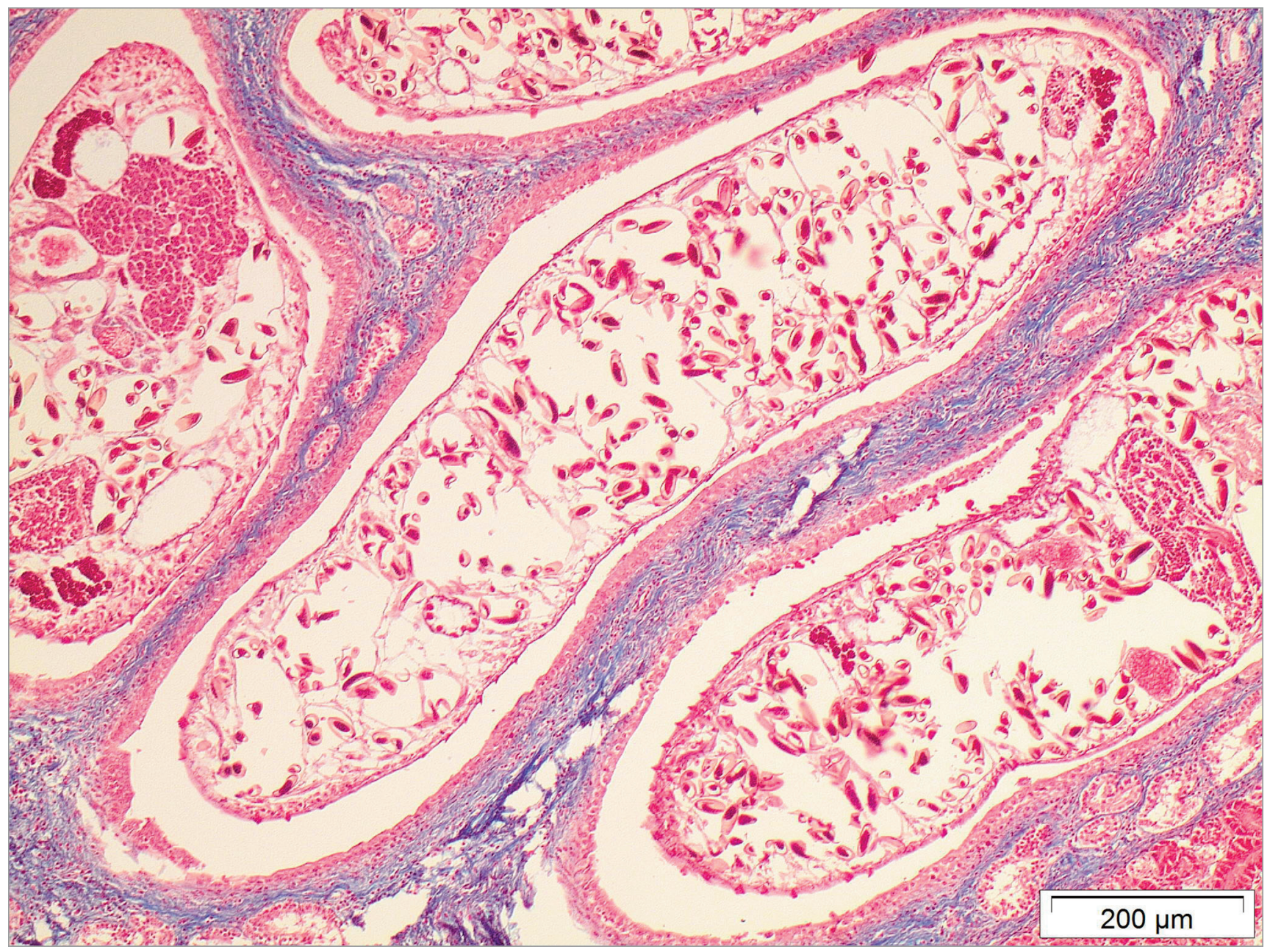

Fig. 3. Cross section of the kidney of a male scarlet macaw (Ara macao) showing severe fibrosing interstitial nephritis in association with a gravid trematode. Masson's trichrome stain

Rica represents a new geographical record for this digenean. Daily careful cage inspection and control programme of terrestrial gastropods should be recommended in all rescue centres located in those countries where P. bragai and its intermediate hosts have been recorded.

Acknowledgements. We thank J. M. Kinsella (Helm West Laboratory, USA) for reviewing the first draft of this manuscript.

\section{References}

Abdo W., Sultan K. 2013. Histopathological findings of the kidney Trematoda Paratanaisia spp. (Digenea: Eucotylidae) in cattle egret (Bubulcus ibis). Revista Brasileira de Parasitologia Veterinaria, 22, 312-313

Barrientos Z. 2003. Lista de especies de moluscos terrestres (Archaeogastropoda, Mesogastropoda, Archaeopulmonata, Stylommatophora, Soleolifera) informadas para Costa Rica. Revista de Biologia Tropical, 51, 293-304

Brandolini S.V., Amato S.B. 2006. Larval development of Paratanaisia bragai (Santos 1934) (Digenea, Eucotylidae) under ex- perimental conditions. Revista Brasileira de Zoologia, 23, $1097-1100$

Brandolini S.V., Amato S.B. 2007. Morfologia externa de espécimenes adultos de Paratanaisia bragai (Santos, 1934) (Digenea: Eucotylidae). Revista Brasileira de Parasitologia Veterinaria, $16,129-132$

Brener B., Tortelly R., Caldas Menezes R., Muniz Pereira L.C., Pinto R. M. 2006. Prevalence and pathology of the nematode Heterakis gallinarum, the trematode Paratanaisia bragai, and the protozoan Histomonas meleagridis in the turkey, Meleagris gallopavo. Memorias do Instituto Oswaldo Cruz, 101, 677-681

Bunbury N., Stidworthy M., Greenwood A., Jones C., Sawmy S., Cole R., Edmunds K., Bell D.J. 2008. Causes of mortality in free-living Mauritian pink pigeons Columba mayeri, 2002 2006. Endangered Species Research, 9, 213-220. DOI: 10.3354/esr00088

Keller D.G., De Barros-Araujo J.L. 1992. Ciclo evolutivo de Paratanaisia bragai (Santos, 1934) (Trematoda, Eucolylidae) com novo hospedeiro intermediario no Brasil: Leptinaria unilamellata (D’Orbigny, 1835) (Gastropoda, Pulmonata, Sublulinidae) em condições de laboratòrio. Revista Brasileira de Parasitologia Veterinaria, 1, 89-92

Luppi M.M., de Melo A.L., Motta R.O.C., Malta M.M.C., Gardiner C.H., Santos R.L. 2007. Granulomatous nephritis in psittaci- 
nes associated with parasitism by the trematode Paratanaisia spp. Veterinary Parasitology, 146, 363-366. DOI: 10.1016/ j.vetpar.2007.03.011

Pérez A., Bornemann G., Campo L., Sotelo M., Ramírez F., Arana I. 2005. Relaciones entre biodiversidad y producción en sistemas silvopastoriles de América Central. Ecosistemas, 14, $132-141$

Received: October 12, 2014

Revised: January 30, 2015

Accepted for publication: March 11, 2015
Santos V. 1934. Monostomose renal das aves domesticas. Revista do Departamento Nacional da Produccao Animal, 1, 203-211

Unwin S., Chantrey J., Chatterton J., Aldhoun J.A., Littlewood D.T. J. 2013. Renal trematode infection due to Paratanaisia bragai in zoo housed Columbiformes and a red bird of paradise (Paradisaea rubra). International Journal for Parasitology, Parasites and Wildlife, 2, 32-41. DOI:10.1016/j.ijppaw.2012. 11.001 